\title{
THE ELECTRIFICATION OF THE ATMOSPHERE.'
}

\section{BY ALEXANDER MCADIE.}

Will the twentieth century number among its triumphs a complete electrical survey of the atmosphere? There are some good grounds for believing that it will.

In the first place, the subject of atmospheric electricity, unlike the commercial problems in electricity, has not been attacked by an army of workers; swarming on each new phase and forcing further development by tireless industry and determined zeal. The appearance of three such papers as are referred to below indicates a quickening and wide-spread interest in the subject. Secondly, although we still lack a guiding theory as to the origin of the earth's negative charge, valuable data are accumulating so rapidly, and are now so accessible, that erroneous hypotheses may be quickly and effectively put to the test and disposed of. And thirdly, in the matter of instrumental equipment, we know the weakness of our present methods and apparatus, and also understand that where so many independent variables are to be dealt with, care must be taken to properly evaluate the electrometer readings. Furthermore, as with problems in meteorology, we must reach out from the individual observations to a series of similar simultaneous ones. The general laws of the potential variation in free air will be forthcoming when the necessary observations are made at many places. It is as logical for one to use a single therriometer to foretell marked temperature changes as to use a quadrant electrometer, and hope to determine from a series of isolated readings much of value concerning the potential of the air.

It is gratifying to note that in all recent investigations the tendency is to interpret observations rather than collect them. Without disparaging the results of early workers, we insist upon work of a different order in future. It is now very well known that the exposure will largely control the values obtained. We have many tables of observations, but all with different exposures, and it is

" Observations on Atmospheric Electricity at the Kew Observatory." By C. Chree, Proc. Royal Soc., vol. 60.

"Review of Recent Investigations in Atmospheric Electricity." By J. ELSTER and H. GeItel. Extract from Part II of the Report of the Chicago Meteorological Congress, August, 1893, pp. 510-522.

"Atmospheric Electricity." Lecture delivered before the Royal Instilution of Great Britain, Februaty 22, I895, by Professor ArThur Schuster. 
rather hard to reconcile the resulting mean values of the potential of the air. Enough of this kind of work has been done.

The following table will give at a glance the work of the chief investigators from the time of Franklin to the end of the eighteenth century. Passing Peter Collinson, of London, who introduced to the notice of the Royal Society the experiments of Franklin, and the three less known workers-J. H. Winkler, who wrote in 1746 on the electrical origin of the weather lights; Maffei, I747; and Barbaret, I750-we have:

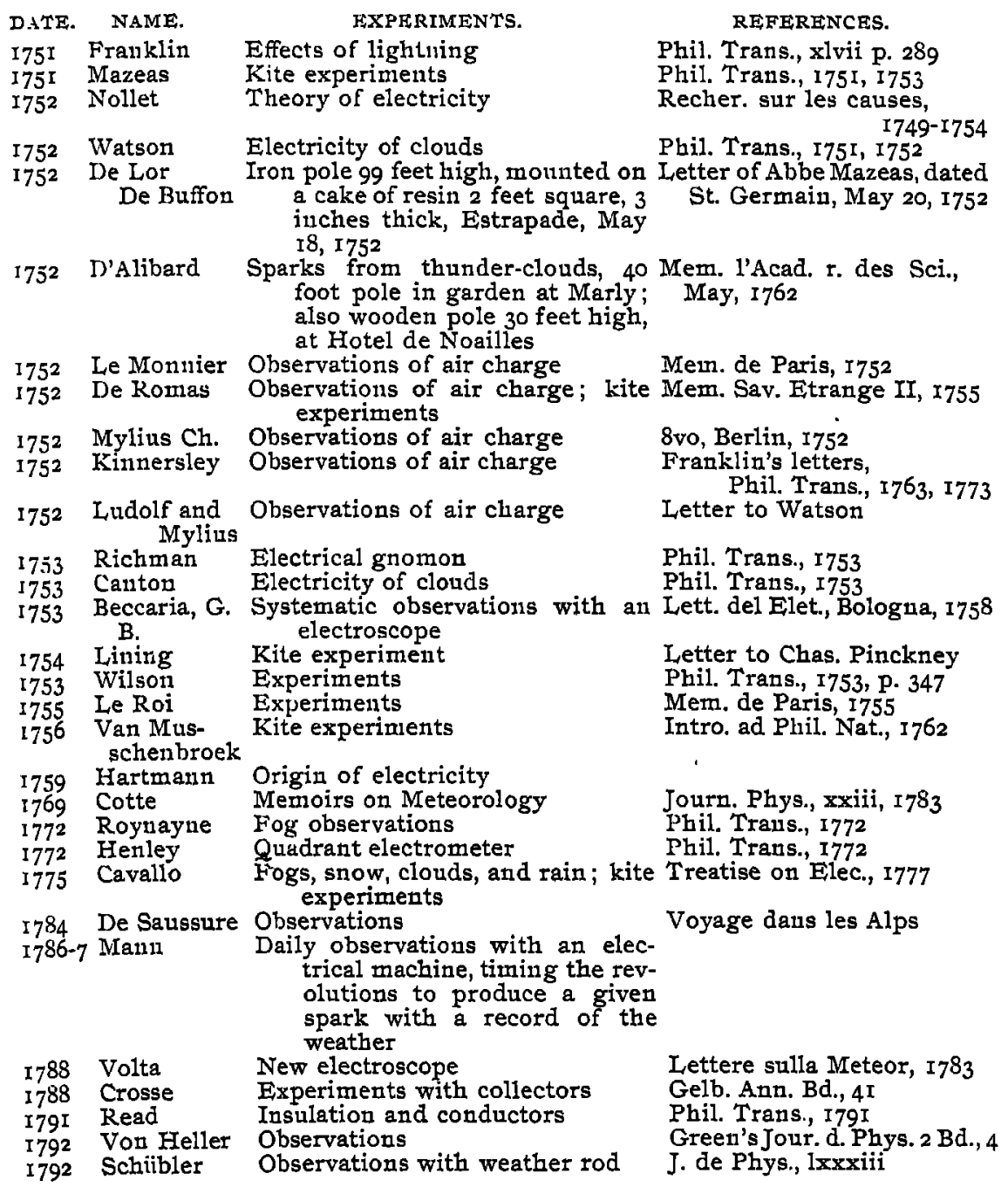


At the beginning of the nineteenth century, Schübler, at Tübingen, systematically observed for twenty years and worked out a curve of diurnal variation. Double maxima and minima were determined; the first maximum about $8 \mathrm{a}$. m., and the second about 8 p. m. The minima occurred before sunrise and about sunset. Correlating the values with weather conditions, Schübler found in I Io cases of rain, 63 negative values and 47 positive ones; while in 33 cases of snow, 27 were positive and 6 negative.

Peltier's modification of the electroscope and his views on the origin of atmospheric electricity led to a series of observations by A. Quetelet, beginning in August, I 842, at the Observatory at Brussels. After some improvements in the electroscope were made, another set of observations was made in 1844 , and it appeared that no negative values were observed except during rain. Indeed, negative values were rare, only 23 cases being recorded in four years. Passing the observations made at Dublin by Clarke in 1839, we come to those made at the Observatory at Munich by I amont, in I850-5I, with a Peltier electrometer and methods about the same as at Brussels. The monthly and annual means are given in Poggendorff's Annalen, 1xxxv, 1852, pp. 494-504, and lxxxix, pp. 258 , et seq. In general, the winter months show a value nearly twice that of the summer months. About the same time, observations were made at Kreuznach by Dellmann. The yearly values nearly agree, but the mean monthly values differ considerably. A minimum occurs in May and a maximum in December. The air was generally positively electrified. Smoke and fog gave high positive values, and dust caused a change from positive to negative for several hours and to a degree exceeding the positive. Rain gave sometimes high positive and sometimes high negative, the latter often when the rain had just ended. Snow almost always gave high positive.

Everett, at Windsor, N. S., made observations, generally three per day, and the results of these and later observations have been widely published, and are too well known for extended notice now. During the same time, Wislizenus, at St. Louis, Missouri, made observations, and has given the annual and diurnal curves of these. Two maxima and two minima are shown in the diurnal curve and a maximum in winter. In all, Wislizenus made some $25,000 \mathrm{ob}-$ servations, and his conclusions are therefore of more weight than those of any other observer up to that time. The normal state of the air is positive, and negative is an exceptional and temporary 
condition. Marked disturbances were experienced at times of thunder storms. Fog was occasionally accompanied by negative indications, but alter fine drizzling rain, fog as a rule was accompanied by positive values, often very high. A full discussion of the observations may be found in the American Mleteorological Journal for 1887 .

We have not space to do more than simply mention most of the other observers. W. A. Birt has given an elaborate discussion of the Kew Observations of $1845^{-6-7}$ in the Report of the British Association, I849, p. Ir3. At Gaud, Duprez studied the observations made from $\mathrm{I} 855$ to $\mathrm{I} 864$, and brings out particularly the relation to cloudiness. Palmieri at Vesuvius, in 1850 , and later with simultaneous observations at Naples and Vesuvius, found that the potential was lower at the higher station. In this conclusion he is at variance with all other observers. Some observations that are worthy of notice were made with a water-dropper collector at Pernambuco, from October, 1876 , to February, I877. On the rare occasions in which a negative potential was recorded, there were heavy rains and more or less cloudiness. We now come to the very important observations made at Paris by Mascart and others under his direction. The apparatus was installed at the College de France in February, 1879, and continuous records covering some years were obtained. In general, the potential of the air was positive. Rain was almost always accompanied by large negative values. The change in character occurs previous to the rain, and sometimes the rain is followed immediately by high positive values. A very full discussion of the observations made by the United States Signal Service is given in the Memoir of the National Academy of Sciences, by Professor T. C. Mendenhall. It is to be regretted that this discussion is not more generally known; for there are many valuable suggestions in it, concerning mechanical collectors, best forms of electrometers, proper exposures, and details of methods to be followed, of great benefit to those who are to take observations. There is also an elaborate discussion of the question, "In the present state of meteorological science, can the observations of atmospheric electricity be utilized in forecasting the weather?" A very thorough set of observations was made by Muiller and Leyst, in Russia, with a Carpentier form of Mascart Electrometer. The mean values for bi-hourly observations made at Pawlowsk in 1884 are given in Annalen des Phy's. Cent. Obs., Part I, r884. Other observations are those made by C. Michie Smith, in Madras, in 1883 
and 1884 ; Abercromby, at the Peak on the Island of Teneriffe; Dr. Fines, at Perpignan, with photographic apparatus of the Mascart pattern, and continued for a number of years. Roiti, Magrini, and Pasquilini have two years' complete records at Florence. Exner's extensive experiments on the potential gradient, Andree's observations near the pole while on the Swedish Expedition, and the work on the Sonnblick by Elster and Geitel, bring us down to the present state of the problem.

The recent Kew experiments were undertaken to verify Exner's law that a building reduces the potential of the air, precisely as if it formed an integral part of the earth's surface. A portable electrometer was carried to five stations near the Observatory, and the mean values of the several ratios found to be approximately constant. The meteorological elements are then discussed, and partic. ularly the moisture, to see whether the potential gradient is so closely connected with the aqueous vapor as Exner claims. The results do not support the theory. The influence of bright sunshine in reducing the potential gradient, as shown by Elster and Geitel, seems more likely. The potential was lower after long sunshine. The evidence "in favor of a connection of high potential with low temperature is just about as strong as that in favor of a connection of high potential with little previous sunshine." Higher potential was found to be associated with higher pressure in the forenoon observations, but to a less marked degree in the afternoon observations. Adopting eleven miles as a limiting value of the wind velocity, it was found that with a mean velocity of 19.6 miles per hour, there was a mean potential of 153 ; and with a mean velocity of 6.8 , the mean potential was I75. The author does not seem to be aware of the observations made in the United States upon similar lines. An attempt was also made to investigate the relation of the potential to cyclonic and anti-cyclonic weather. In five cases out of the seven considered, the mean potential for the anti-cyclonic coudition exceeded that for the cyclonic. In Dr. Chree's words, "There is something to be said for the hypothesis : but individual occurrences of high potential in cyclonic weather and of low potential in anti-cyclonic weather were not infrequent."

The paper of $\mathrm{J}$. Elster and $\mathrm{H}$. Geitel is a most comprehensive review of recent investigations in the subject. For painstaking and systematic study of the potential as influenced by water vapor, sunlight, dust, and height, it cannot be excelled. 
The views of von Bezold and Arrhenius concerning a photoelectric action of the solar radiation have been in part confirmed by these investigators. It has been experimentally shown that the sun's rays act on certain substances in such a way as to cause a loss of negative electricity. Our authors make the potential gradient vary with exposure to ultraviolet light. The marked disturbances occurring with precipitation are considered as disturbances of the normal field. They also think that Palmieri is right in his statement that whenever negative electricity is observed, rain falls close by. Sohncke and Luvini have shown how dry ice crystals were positively electrified through friction with dust-formed water, and Maclean and Goto, and more recently Lenard and Kelvin, have discussed the question of electrification through falling water. "When waterdrops strike on a fixed moist substratum or a larger water surface, the surrounding air at the time of impact shows itself as negatively electrified." And our authors think, with Lenard, that it is very probable that the negative values so prevalent during rainy weather are in part due to this. With the building of mountain observatories, the electric phenomena of the air, and more especially the silent discharges, come more readily under our observation. Elster and Geitel themselves have collected a number of observations relating to the appearance of St. Elmo's fire on the Sonnblick. It would seem that the phenomena are closely connected with climatic conditions and are to be studied in their development precisely as thunderstorms.

Elster and Geitel have rendered a great service to future students of atmospheric electricity, by clearly pointing out the difference between the normal field or fair-weather electricity and the accidental field, if it may be so called, when the electrical measurements are greatly influenced by dust, snow, clouds, precipitation, whirling air or smoke, spattering water, etc. "Certainly it is an improvement," they say, "to diminish the influence of the lower dusty strata of air through the employment of kites, as introduced by McAdie at Blue Hill, and later by Weber at Kiel, though it is questionable if the advantage is not too dearly bought by the impossibility of determining the height." Marked improvements have been made in kite methods since these words were written. Another important matter, touched upon by our authors, is the circulation of electricity from the earth into the atmosphere, and back again to earth. Theories are not wanting, but experimental determinations. are. It is not improbable that a link in the chain of processes may 
be the aurora, and investigations in this direction are therefore greatly desired. Through such will the relation between the electric and magnetic fields be brought out. This is, in our opinion, the coming question, "How are the magnetic elements and the electrical currents of the air related?"

Professor Schuster's lecture is a most interesting résumé of the experimentation of Franklin's time with the modern lecture apparatus for studing the conduction of gases. The question of the breaking down of the air as an insulating medium is touched upon, and the effect of light and of the discharge itself considered. Electric sparks are liable to succeed each other along the same path, and Schuster thinks this points to a higher conductivity. of the air along the path of the previous discharge. Schuster also thinks that the location of the positive charge, corresponding to the earth's negative charge, can only be ascertained through the agency of balloon and kite experiments. "Observations made up to heights of about $I, 000$ feet seem to indicate a strengthening of the electric field-i.e., the fall of potential per meter is greater at a height of, say, 200 meters than on the surface of the earth." The observations of Dr. Leonhard Weber and Dr. Baschin are referred to-the former as showing how the fall of potential at a height of 350 meters was six times that at the earth's level; and the latter showing that at a height of 3,000 meters no fall could be determined, while at $760,2,400$, and 2,800 meters respectively, the fall in volts per meter was 49,28 , and I 3 respectively. It seems therefore likely that the lines of force of the normal electric field of the earth end within the first 10,000 or 15,000 feet. Schuster advances the somewhat startling view that the semidiurnal variation of atmospheric electricity is connected with "the same circulation in the upper regions of the atmosphere which shows itself in the corresponding changes in pressure." He refers to Exner's formula: $P=\frac{A}{r+k p_{10}}$, where $\mathrm{A}=\mathrm{I} 300, \mathrm{k}=\mathrm{I} 3 \cdot \mathrm{I}$, $p_{0}=$ pressure of aqueous vapor present, in centimeters, and $P=$ the electric force; and notes the agreement between vapor pressures 0.23 and 0.95 . It is the amount of vapor, and not the humidity, which controls. Elster and Geitel's ultraviolet radiation relation to electrification and amount of aqueous vapor present is also alluded to. 